\title{
Predicting Value of Different Ultrasound Markers for Diagnosing Morbidly Adherent Placenta and Associated Complications
}

\author{
Mojgan Barati ${ }^{1}$, Mahvash Zargar $^{1}$, Mahin Najafian$^{1}$, Najmie Saadati ${ }^{1}$, Maryam Rekabizadeh $^{{ }^{*}(\mathbb{D}}$
}

\begin{abstract}
Objectives: This study was conducted to evaluate the importance of different sonographic findings in the detection of the morbidly adherent placenta (MAP) among pregnant women and then to assess the correlation between delivery complications and ultrasonographic findings.

Materials and Methods: This analytical and prospective study was conducted on 150 pregnant women with a previous history of a cesarean section from 2015 to 2017. The sonographic findings included the location of the placenta, retroplacental aliasing, bulging toward the bladder, lacuna, and the lack of sonolucent area behind the placenta. Finally, these patients were followed until delivery and their complications were assessed as well.

Results: Of 150 previous cesarean sectioned patients, 101 (67.3\%) cases had not sonographic findings of MAP. No morbidity was found in those with no sonographic findings of MAP. Fifty-nine pregnant mothers had the sonographic criteria of MAP prior to delivery, of whom 39 (80\%) patients had MAP during the cesarean section. In 39 patients with confirmed MAP, 27 cases underwent a hysterectomy and 12 received special procedures for uterus reservation. In addition, 8 cases had bladder rupture, 25 cases experienced ICU hospitalization, and 33 cases needed a blood transfusion. Of these 39 confirmed MAP, $31(79.48 \%)$ and 8 patients (20.51\%) had previa and an anterior placenta without previa, respectively. Finally, no mortality was reported in the current study.

Conclusions: In general, the most important sonographic factors on predicting MAP were the location of placenta, the aliasing and bulging while lacuna and the lack of sonolucent area had less value. The results demonstrated 93\%, 100\%, 90\%, 79.59\%, and 100\% accuracy, sensitivity, specificity, as well as positive and negative predictive values for the prediction of MAP by ultrasonography, respectively.

Keywords: Cesarean section, Placenta previa/accrete, Hysterectomy, Third trimester
\end{abstract}

\section{Introduction}

The morbidly adherent placenta (MAP) has become a major obstetric challenge in the last decades. It presents a spectrum of conditions that are classified into placenta accreta, increta, and percreta based on the degree of trophoblastic invasion through the myometrium and uterine serosa (1). MAP is defined as the abnormal attachment of the placenta to the myometrium without intervening decidua (2) and significantly increases the rate of maternal morbidity and mortality mostly due to bleeding, local organ damage, hysterectomy (33\%-50\%), and postoperative complications (3). The incidence of the MAP has approximately risen 13-fold since the early 1900 s and is directly associated with the increasing rate of cesarean delivery (2). In addition to the previous cesarean, other risk factors included curettage, myomectomy, multiparity, pelvic radiation, and endometrial ablation. Further, MAP occurs in $9.3 \%$ and $0.04 \%$ of women with and without placenta previa, respectively (4). There are still large knowledge gaps about defined optimal management for MAP, especially in the setting of diagnosis, perinatal care, the time of delivery, and interventional procedures. The optimal care for women with MAP disorder should be based on accurate and recent prenatal information that allows women and the treatment team to get prepared for the complications that may associate the delivery (2). Clinicians routinely utilize ultrasonography for the identification of MAP.

Although ultrasound is typically used as a diagnostic modality for MAP, the diagnostic value and accuracy still need more investigations. Most studies conducted on small cohorts (5-9) and some larger studies $(10,11)$ used different modalities and diagnostic criteria in this regard. Given the above-mentioned explanations, this study was carried out to evaluate the importance of different ultrasound findings in the diagnosis of MAP among pregnant women and its prognostic values in predicting postoperative complications.

\section{Materials and Methods}

Study Design

This analytical prospective study was performed in Imam 
Khomeini Hospital affiliated with Ahvaz Jundishapour University of Medical Sciences. All pregnant women, including those referred from other centers, with a history of a previous cesarean section and presenting placenta previa, anterior placenta, posterior low placenta, or those with placenta accreta were included in the study. However, patients that refused to participate and those who had no experience of a cesarean section at our center were excluded from the study.

\section{Measurement}

Transabdominal ultrasound examinations were performed on each woman by a single operator (an expert perinatologist) during the second or third trimester of pregnancy using two-dimensional (2D) grayscale and color ultrasonography, as well as an ultrasound modality equipped with a 4 to $8-\mathrm{MHz}$ transabdominal transducer (LS22EMU1HS ZS01, Sumsung Healthcare, Korea). Different sonographic findings were determined, including the location of placenta (previa or non-previa), retroplacental aliasing, bulging toward the bladder, lacuna, and the lack of subplacental sonolucent area. In addition, variables such as maternal age, the number of previous cesarean sections, the gestational age at delivery (week), and the postoperative length of the stay (day). The patients were followed up until delivery at the referral hospital of Imam Khomeini in Ahwaz (a multidisciplinary hospital). The final diagnosis of MAP was made base on nonspontaneous placental expel, followed by a hysterectomy, blood transfusion, bladder injury, special procedures for uterine saving, and ICU admission.

\section{Statistical Analysis}

All data were analyzed by descriptive statistics including mean, median, standard deviation, and frequency. The data distribution was checked by the KolmogorovSimonov test and the independent $t$ test of the MannWhitney U test was used to compare the means. Eventually, the proportions were compared by the Chi-square test. All analyses were performed by SPSS, version 19 and $P<0.05$ was considered significant.

\section{Results}

A total of 150 cases were evaluated during the study and $49(32.6 \%)$ cases were diagnosed with MAP based on ultrasound findings. Further evaluations confirmed MAP in 39 cases while the other 101 patients had no
MAP-related sonographic criteria and were confirmed as non-MAP cases. Tables S1 and S2 summarize the clinical details of patients presenting MAP-related sonographic criteria, including 39 cases with confirmed MAP and 10 cases diagnosed as non-MAP cases (Supplementary file 1).

Previa and non-previa were found in 31 (79\%) and 8 (21\%) patients with confirmed MAP diagnosis, respectively. Of 49 suspicious MAP patients, 18 cases (37\%) underwent emergency cesarean section, including 10 due to labor pain and 8 due to bleeding.

Furthermore, 39 cases with confirmed MAP either underwent hysterectomy $(\mathrm{n}=27,69.23 \%)$ or uterus preservation by special procedures $(n=12,30.76 \%)$ that included bilateral hypogastric (internal iliac) arties ligation and partial myometrial resection $(n=8)$, bilateral uterine artery ligation and hemostatic sutures at the placental site $(n=3)$, and one case hemostatic suture only $(n=1)$. The patients also experienced bladder rupture $(n=8)$, ICU admission $(n=25)$, and blood transfusion $(n=33)$. The mortality rate in both procedures was zero.

Table 1 compares the complications associated with procedures (hysterectomy vs. special procedures) performed for 39 MAP cases. None of the patients undergoing special procedures had bladder rupture while 8 (30\%) out of 27 cases in the hysterectomy group experienced bladder rupture $(P=0.001)$. Similarly, the transfusion of fresh frozen plasma $(P=0.001)$, packed cell $(P=0.03)$, and ICU admission $(P=0.003)$ were significantly lower in patients treated by uterus preservation procedures when compared with those managed by hysterectomy.

Table 2 presents complications associated with sonographic findings among women with MAP $(n=39)$. Bulging to the bladder was the only statistically significant predicting factor for hysterectomy. There was no correlation between the other sonographic findings and complications.

The patients' mean age was 31.7 years. In general, $28.6 \%$, $42.9 \%$, and $28.6 \%$ of patients experienced a cesarean section once, twice, and three or more times, respectively.

The median gestational age at delivery was 36 weeks (17- 381/7 weeks). Moreover, the mean gestational age at termination was $371 / 7$ weeks in non-MAP cases (only sonographic MAP) treated by elective surgery. However, it was 356/7 weeks in patients with confirmed MAP with the viable fetus (gestational age $>24$ weeks) treated by the elective procedures $(n=21)$.

Additionally, retroplacental aliasing, bulging toward

Table 1. Maternal Outcome in 39 Pregnancies With Morbidly Adherent Placenta According to the Type of Intervention During Cesarean Section

\begin{tabular}{lccc}
\hline Complications & Hysterectomy $(\mathbf{n}=\mathbf{2 7})$ & Uterine Maintenance Procedures $(\mathbf{n}=\mathbf{1 2})$ & $0(0)$ \\
Bladder rupture & $8(30 \%)$ & $0.4 \pm 1.1$ & 0.001 \\
Fresh frozen plasma (unit) & $1.3 \pm 1.5$ & $0.6 \pm 0.7$ & 0.001 \\
Packed cell (unit) & $2.8 \pm 1.8$ & $3.1 \pm 1.1$ & 0.03 \\
Postoperative hospital stay (day) & $5.2 \pm 1.3$ & 0.003 \\
\hline
\end{tabular}

Note. Data are expressed as n (\%) or median (range). The Mann-Whitney U-test was utilized to compare continuous variables and Fisher's exact test was utilized for categorical variables. 
Table 2. Complications Associated With Sonographic Findings Among Women With MAP $(n=39)$

\begin{tabular}{|c|c|c|c|c|c|c|c|c|c|c|c|c|}
\hline \multirow{2}{*}{ Complication } & \multicolumn{3}{|c|}{ Aliasing } & \multicolumn{3}{|c|}{ Bulging } & \multicolumn{3}{|c|}{ Lacuna } & \multicolumn{3}{|c|}{$\begin{array}{c}\text { Lack of Subplacental } \\
\text { Sonolucent Area }\end{array}$} \\
\hline & $\begin{array}{c}\text { Yes } \\
(n=34)\end{array}$ & $\begin{array}{c}\text { No } \\
(n=5)\end{array}$ & $\begin{array}{c}P \\
\text { Value }\end{array}$ & $\begin{array}{c}\text { Yes } \\
(n=23)\end{array}$ & $\begin{array}{c}\text { No } \\
(n=16)\end{array}$ & $\begin{array}{c}P \\
\text { Value }\end{array}$ & $\begin{array}{c}\text { Yes } \\
(n=36\end{array}$ & $\begin{array}{c}\text { No } \\
(n=3)\end{array}$ & $\begin{array}{c}\mathbf{P} \\
\text { Value }\end{array}$ & $\begin{array}{c}\text { Yes } \\
(n=35)\end{array}$ & $\begin{array}{c}\text { No } \\
(n=4)\end{array}$ & $\begin{array}{c}P \\
\text { Value }\end{array}$ \\
\hline Hysterectomy ( $n=27)$ & 24 & 3 & 0.6 & 19 & 8 & 0.03 & 25 & 2 & 0.9 & 23 & 4 & 0.1 \\
\hline Bladder rupture $(n=8)$ & 7 & 1 & 0.9 & 7 & 1 & 0.06 & 7 & 1 & 0.5 & 8 & 0 & 0.2 \\
\hline ICU hospitalization ( $n=25)$ & 22 & 3 & 0.8 & 16 & 9 & 0.3 & 23 & 2 & 0.9 & 21 & 4 & 0.1 \\
\hline Transfusion (n=33) & 30 & 3 & 0.1 & 21 & 12 & 0.1 & 30 & 3 & 0.4 & 29 & 4 & 0.3 \\
\hline Pack cell & $\begin{array}{c}2.3 \\
(0-7)\end{array}$ & $\begin{array}{c}1 \\
(0-2)\end{array}$ & 0.14 & $\begin{array}{l}2.21 \\
(0-6)\end{array}$ & 2.06 & 0.8 & $2(0-6)$ & $\begin{array}{c}3.3 \\
(1-7)\end{array}$ & 0.26 & $\begin{array}{c}0.9 \\
(0-7)\end{array}$ & $0(0-0)$ & 0.23 \\
\hline Fresh frozen plasma & $0.9(0-4)$ & 0 & 0.17 & $\begin{array}{l}1.17 \\
(0-4)\end{array}$ & $\begin{array}{l}0.31 \\
(0-3)\end{array}$ & 0.06 & $\begin{array}{c}0.8 \\
(0-4)\end{array}$ & $\begin{array}{c}0 \\
(0-0)\end{array}$ & 0.31 & $\begin{array}{c}2.2 \\
(0-4)\end{array}$ & 1.75 & 0.65 \\
\hline Postoperative days & 4.16 & 3.8 & 0.3 & 4.9 & 3.93 & 0.066 & 4.44 & 5.33 & 0.37 & 4.51 & 4.5 & 0.98 \\
\hline
\end{tabular}

Note. Data are expressed as number, mean \pm SD or median (range). SD: Standard deviation; MAP: Morbidly adherent placenta; ICU: Intensive care unit.

the bladder, as well as lacuna and the lack of subplacental sonolucent area were positive in $34,23,36$, and 35 cases with confirmed MAP, respectively. The accuracy, sensitivity, specificity, along with positive and negative predictive values (PPV and NPV) were 93\%, $100 \%, 90 \%, 79.59 \%$, and $100 \%$ for the prediction of MAP by ultrasonography, respectively. According to Table 3, among different sonographic markers, bulging had 100\% PPV for diagnosis of MAP and aliasing had $94 \%$.

\section{Discussion}

The results revealed that ultrasound criteria could accurately diagnose MAP diseases in around $80 \%$ of cases. The ultrasound had high accuracy, sensitivity, specificity, as well as PPV and NPV in the diagnosis of MAP (93\%, $100 \%, 90 \%, 79.59 \%$, and $100 \%$, respectively). Due to the high sensitivity, Ultrasound evaluation could be suggested as an appropriate diagnostic test in diagnosing MAP. Our findings are in line with those of previous studies $(12,13)$. The findings indicated that aliasing and bulging had the highest PPV and specificity in diagnosing the MAP. Although the sensitivity of bulging was less than the other criteria, the PPV was $100 \%$ and hence, it could be a useful marker in MAP diagnosis. The PPV of aliasing was also very high. On the other hand, lacuna and the lack of sonolucent area had less diagnostic values. Although providing the high sensitivity, these two criteria had low specificity, and thus demonstrated more false-positive diagnosis. Pilloni et al (14), Calì et al (11), and Fujisaki et al (13) also showed that lacuna had a low PPV in diagnosing MAP. In our study and the above-mentioned studies, only the presence of lacuna was evaluated although in some previous studies, in addition to the presence of lacuna, its number in the placenta was assessed as well $(15,16)$. Therefore, it is more useful in ruling out the MAP diagnosis due to the low PPV of the lacuna.

The other important marker in diagnosing MAP is the location of the placenta. Based on our data, $79 \%(\mathrm{n}=31)$ of patients had previa and $21 \%(n=8)$ of other patients had anterior placenta without previa. Thus, the MAP can also be present in non-previa placenta. In our study, MAP patients with non-previa placenta were diagnosed by ultrasound.

There are two main options for managing MAPincluded special procedures for uterus preservation and immediate cesarean hysterectomy. In the current study, $27(69.2 \%)$ patients with confirmed MAP underwent a hysterectomy and the other 12 cases were managed by uterus preservative procedures. This is consistent with the finding of Pilloni et al (14) which indicated that the rate of

Table 3. Accuracy of Ultrasound Findings in MAP Diagnosis

\begin{tabular}{|c|c|c|c|c|c|}
\hline Variables & Sonography & Aliasing & Bulging & Lacuna & Lack of Area \\
\hline Sensitivity & 1.00 & 0.87 & 0.59 & 0.92 & 0.10 \\
\hline $95 \%$ confidence interval & $0.90-1.0$ & $0.72-0.95$ & $0.42-0.74$ & $0.79-0.98$ & $0.028-0.24$ \\
\hline Specificity & 0.91 & 0.80 & 1.00 & 0.20 & 0.90 \\
\hline $95 \%$ confidence interval & $0.84-0.95$ & $0.44-0.97$ & $0.69-1.0$ & $0.02-0.55$ & $0.55-0.99$ \\
\hline Positive predictive value & 0.80 & 0.94 & 1.00 & 0.82 & 0.80 \\
\hline 95\% confidence interval & $0.65-0.89$ & $0.81-0.99$ & $0.85-1.0$ & $0.67-0.91$ & $0.28-0.99$ \\
\hline Negative predictive value & 1.00 & 0.62 & 0.38 & 0.40 & 0.20 \\
\hline $95 \%$ confidence interval & $0.96-1.0$ & $0.31-0.86$ & $0.20-0.59$ & $0.05-0.85$ & $0.09-0.35$ \\
\hline
\end{tabular}

Note. MAP: morbidly adherent placenta. 
hysterectomy was $56 \%$ while it is extremely less than the report of Bailit et al (30\%). The rate of hysterectomy in cases of confirmed MAP varied between 30\% and 55\% in other studies (2).

Treatment-associated complications including bladder rupture $(n=8)$, ICU admission $(n=25)$, and blood transfusion $(n=33)$ were observed during the study. The frequency of MAP complications was similar to previous reports $(13,17)$. The present study further assessed the value of ultrasonography criteria in predicting patients' outcomes. These complications were less in special procedures with the reserved uterus compared to hysterectomy. Moreover, the bulging to the bladder was the only statistically significant predicting factor for hysterectomy. There was no significant statistical relationship between other sonographic findings and complications and the mortality rate was zero in both procedures.

The mean gestational age at termination was $371 / 7$ weeks in non-MAP cases treated by elective surgery. However, in patients with confirmed MAP with the viable fetus (gestational age $>24$ weeks) treated by elective procedures $(n=21)$, the gestational age at termination was 356/7 weeks. In addition, non-map cases presented less important sonographic markers such as lacuna and the lack of area, therefore, the gestational age at termination was considered higher than those presented high accurate sonographic markers such as aliasing and bulging.

\section{Conclusions}

Overall, our findings provided useful criteria for determining, managing, and risk stratifying MAP patients through sonography as the most widely available tool. The most important sonographic factors on predicting MAP were the location of the placenta, aliasing and bulging while lacuna and the lack of sonolucent area had less values. Based on the findings, high accuracy (93\%), sensitivity (100\%), specificity (90\%) in addition to positive $(79.59 \%)$ and negative $(100 \%)$ predictive values (PPV and NPV) were observed for the prediction of MAP by ultrasonography, respectively. Ultrasound appearance, especially aliasing and bulging is a useful tool for the diagnosis of MAP (highest PPV and specificity). Our study had some limitations. It included a small number of patients and thus the results could not generalize and must be confirmed by further studies. Therefore, future studies could be done on a large cohort of patients in order to evaluate the long-term prognostic values of the markers.

\section{Conflict of Interests}

Authors declare that they have no conflict of interests.

\section{Ethical Issues}

All procedures performed in studies involving human participants were in accordance with the ethical standards of the Local Ethics Committee of Ahvaz University of Medical Sciences (IR.AJUMS.REC.1397.226) and with the
1964 Helsinki declaration. Written informed consent was obtained from all patients and normal individuals.

\section{Financial Support}

Authors received no financial support for the research.

\section{Acknowledgments}

We wish to thank all our colleagues at Imam Khomeini Hospital, Ahvaz, Iran.

\section{Supplementary Materials}

Supplementary file 1 contains Tables S1 and S2.

\section{References}

1. Doumouchtsis SK, Arulkumaran S. The morbidly adherent placenta: an overview of management options. Acta Obstet Gynecol Scand. 2010;89(9):1126-1133. doi:10.3109/000163 49.2010.503869

2. Bailit JL, Grobman WA, Rice MM, et al. Morbidly adherent placenta treatments and outcomes. Obstet Gynecol. 2015;125(3):683-689. doi:10.1097/aog.0000000000000680

3. Wright JD, Pri-Paz S, Herzog TJ, et al. Predictors of massive blood loss in women with placenta accreta. Am J Obstet Gynecol. 2011;205(1):38.e31-36. doi:10.1016/j. ajog.2011.01.040

4. Kaufman C, Tadros A. Endovascular interventions for the morbidly adherent placenta. J Clin Med. 2018;7(5). doi:10.3390/jcm7050092

5. Finberg HJ, Williams JW. Placenta accreta: prospective sonographic diagnosis in patients with placenta previa and prior cesarean section. J Ultrasound Med. 1992;11(7):333343. doi:10.7863/jum.1992.11.7.333

6. Chou MM, Ho ES, Lee YH. Prenatal diagnosis of placenta previa accreta by transabdominal color Doppler ultrasound. Ultrasound Obstet Gynecol. 2000;15(1):28-35. doi:10.1046/ j.1469-0705.2000.00018.x

7. Dwyer BK, Belogolovkin V, Tran L, et al. Prenatal diagnosis of placenta accreta: sonography or magnetic resonance imaging? J Ultrasound Med. 2008;27(9):1275-1281. doi:10.7863/jum.2008.27.9.1275

8. Wong HS, Cheung YK, Zuccollo J, Tait J, Pringle KC. Evaluation of sonographic diagnostic criteria for placenta accreta. J Clin Ultrasound. 2008;36(9):551-559. doi:10.1002/ jcu.20524

9. Elhawary TM, Dabees NL, Youssef MA. Diagnostic value of ultrasonography and magnetic resonance imaging in pregnant women at risk for placenta accreta. J Matern Fetal Neonatal Med. 2013;26(14):1443-1449. doi:10.3109/147670 58.2013.784740

10. Shih JC, Palacios Jaraquemada JM, Su YN, et al. Role of three-dimensional power Doppler in the antenatal diagnosis of placenta accreta: comparison with gray-scale and color Doppler techniques. Ultrasound Obstet Gynecol. 2009;33(2):193-203. doi:10.1002/uog.6284

11. Calì G, Giambanco L, Puccio G, Forlani F. Morbidly adherent placenta: evaluation of ultrasound diagnostic criteria and differentiation of placenta accreta from percreta. Ultrasound Obstet Gynecol. 2013;41(4):406-412. doi:10.1002/uog. 12385

12. Comstock $\mathrm{CH}$. The antenatal diagnosis of placental attachment disorders. Curr Opin Obstet Gynecol. 
2011;23(2):117-122. doi:10.1097/GCO.0b013e328342b730

13. Fujisaki M, Furukawa S, Maki Y, Oohashi M, Doi K, Sameshima H. Maternal morbidity in women with placenta previa managed with prediction of morbidly adherent placenta by ultrasonography. J Pregnancy. 2017;2017:8318751. doi:10.1155/2017/8318751

14. Pilloni E, Alemanno MG, Gaglioti P, et al. Accuracy of ultrasound in antenatal diagnosis of placental attachment disorders. Ultrasound Obstet Gynecol. 2016;47(3):302-307. doi:10.1002/uog. 14893

15. Fitzpatrick KE, Sellers S, Spark P, Kurinczuk JJ, Brocklehurst $\mathrm{P}$, Knight M. Incidence and risk factors for placenta accreta/ increta/percreta in the UK: a national case-control study. PLoS One. 2012;7(12):e52893. doi:10.1371/journal. pone. 0052893

16. Bowman ZS, Eller AG, Kennedy AM, et al. Interobserver variability of sonography for prediction of placenta accreta. J Ultrasound Med. 2014;33(12):2153-2158. doi:10.7863/ ultra.33.12.2153

17. Cheraghi F, Saadati N, Nazari Z. Maternal and neonatal outcoms of placenta previa at a Tertiary Maternity Hospital Ahvaz, Islamic Republic of Iran. Int J Med Sci Clin Invent. 2017;4(4):2834-2838. doi:10.18535/ijmsci/v4i4.05

(c) 2020 The Author(s); This is an open-access article distributed under the terms of the Creative Commons Attribution License (http:// creativecommons.org/licenses/by/4.0), which permits unrestricted use, distribution, and reproduction in any medium, provided the original work is properly cited. 